\title{
COMPARATIVE STUDY OF NEW SPECTROPHOTOMETRIC METHODS; AN APPLICATION ON PHARMACEUTICAL BINARY MIXTURE OF CIPROFLOXACIN HYDROCHLORIDE AND HYDROCORTISONE
}

\author{
HAYAM M. LOTFY ${ }^{a}$, NAGIBAY. HASSAN ${ }^{a}$, SAMIA M. ELGIZAWY ${ }^{b}$ SARAH S. SALEH ${ }^{c^{*}}$ \\ ${ }^{a}$ Analytical Chemistry Department, Faculty of Pharmacy, Cairo University, Kasr-El Aini Street, 11562 Cairo, Egypt \\ ${ }^{b}$ Analytical Chemistry Department, Faculty of Pharmacy, Assuit University, 71515 Assuit, Egypt \\ cAnalytical Chemistry Department, Faculty of Pharmacy, October University for Modern Sciences and Arts (MSA), \\ $117876^{\text {th }}$ October City, Egypt.
}

(Received: October 14, 2012 - Accepted: March 15, 2013)

\begin{abstract}
Simple, specific, accurate and precise spectrophotometric methods were developed and validated for simultaneous estimation of Ciprofloxacin hydrochloride (CIP) and Hydrocortisone (HYD) in their pure form and pharmaceutical dosage form. Two new spectrophotometric methods were applied: extended ratio subtraction (EXRSM) and ratio difference (RDSM) methods. The results were compared to three well-established methods: Mean centering of ratio spectra method (MCR), Isoabsorpative point spectrophotometric method (IsoM) and Absorbance ratio method (ARM). The linearity range for the spectrophotometric methods was found to be (2-14 $\mu \mathrm{g} / \mathrm{mL})$ and $(1-14 \mu \mathrm{g} / \mathrm{mL})$ for CIP and HYD respectively. The selectivity of the developed methods was investigated by analyzing laboratory prepared mixtures of the two drugs and their combined dosage form. The results obtained from the proposed methods were statistically compared using one-way analysis of variance (ANOVA) where no significant difference was observed between the new (EXRSM and RDSM) and the well-established methods which prove their validity for the analysis of this binary mixture. The methods were validated as per ICH guidelines regarding accuracy, precision, repeatability and robustness; which were found to be within the acceptable limits. The new methods were simple, sensitive and don't need a special program, so they could be easily applied as alternative methods to LC methods in quality control laboratories lacking the required facilities for those techniques.
\end{abstract}

Keywords: Ciprofloxacin; Hydrocortisone; extended ratio subtraction; ratio difference; mean centering; isoabsorpative point.

\section{INTRODUCTION}

Ciprofloxacin hydrochloride (CIP) [1-Cyclopropyl-6-fluoro-1,4dihydro-4-oxo-7-(1-piperazinyl)-3-quinolinecarboxylic acid], is a fluoroquinolone antibacterial agent which is active against wide range of bacteria. Hydrocortisone (HYD) [(11 $\beta)$-11, 17, 21-Trihydroxypregn-4-ene-3, 20 -dione], is corticosteroid with both glucocorticoid and to a lesser extent mineralocorticoid activity ${ }^{1,2}$. Their structures are shown in Fig. 1. These drugs are being used as an ear preparation to treat outer ear infections and reduce swelling.

A survey of the literature revealed the reported methods for the determination of CIP such as UV spectrophotometry ${ }^{3-5}$, HPLC ${ }^{6,7}$, TLC ${ }^{8,9}$ capillary electrophoresis ${ }^{10,11}$ and chemometric ${ }^{12,13}$. The methods reported for HYD such as UV spectrophotometry ${ }^{14}$, HPLC ${ }^{15-17}$, micellar electrokinetic capillary chromatography ${ }^{18,19}$ and capillary electrophoresis ${ }^{20}$.

Simultaneous determination of CIP and HYD has been reported in the literature by HPLC method 21 and chemometric method ${ }^{22}$. No spectrophotometric methods have been reported for the analysis of this mixture. Our aim was the to analyze this binary mixture by two new spectrophotometric methods: extended ratio subtraction (EXRSM) and ratio difference (RDSM) methods; and three well established spectrophotometric methods: mean centering of ratio spectra (MCR), isoabsorpative point coupled with second derivative spectrophotometry and absorbance ratio methods.

Theory of the methods

Extended ratio subtraction spectrophotometric method (EXRSM)

Lotfy et Hagazy ${ }^{23}$ introduced the Extended ratio subtraction method (EXRSM). It starts with the ratio subtraction method (RS) ${ }^{24}$. For a binary mixture of $(\mathrm{X})$ and $(\mathrm{Y}),(\mathrm{X})$ can be determined by dividing the spectrum of the mixture $(\mathrm{X}+\mathrm{Y})$ by a known concentration of $\mathrm{Y}$ as a divisor $\left(\mathrm{Y}^{\prime}\right)$. The division will give a new curve that represents $\mathrm{X} / \mathrm{Y}^{\prime}+\left[\mathrm{Y}^{\prime} \mathrm{Y}^{\prime}=\right.$ constant]. Measure the value of $Y / Y^{\prime}$ constant in the plateau region. If we subtract this constant value, then multiply the obtained curve after subtraction by Y' (the divisor), therefore we can obtain the zero order absorption spectrum $\mathrm{D}_{0}$ of $\mathrm{X}$ (original spectrum of $\mathrm{X}$ ).

$$
\begin{aligned}
& (\mathrm{X}+\mathrm{Y}) / \mathrm{Y}^{\prime}=\mathrm{X} / \mathrm{Y}^{\prime}+\mathrm{Y} / \mathrm{Y}^{\prime}=\mathrm{X} / \mathrm{Y}^{\prime}+\text { constant } \\
& \mathrm{X} / \mathrm{Y}^{\prime}+\text { constant }- \text { constant }=\mathrm{X} / \mathrm{Y}^{\prime} \quad \text { and then } \quad \mathrm{X} / \mathrm{Y}^{\prime} \quad \mathrm{X} \\
& \mathrm{Y}^{\prime}=\mathrm{X}
\end{aligned}
$$

To determine the second component (Y), an extension of the already developed method has been established as a new approach in which Y could be determined by dividing the obtained $\mathrm{D}_{0}$ spectrum of $\mathrm{X}$ by a known concentration of $X$ as a divisor $\left(X^{\prime}\right)$ to get the value of the represents $X / X^{\prime}=$ constant. Dividing the spectrum of the mixture $(\mathrm{X}+\mathrm{Y})$ by the same divisor $\left(\mathrm{X}^{\prime}\right)$, the division will give a new curve that represents $\mathrm{X} / \mathrm{X}^{\prime}+\mathrm{Y} / \mathrm{X}^{\prime}$ where $\mathrm{X} / \mathrm{X}^{\prime}$ is the previously obtained constant. If we subtract this constant, then multiply the obtained curve after subtraction by X' (the divisor), therefore we can obtain the zero order absorption spectrum $\left(\mathrm{D}_{0}\right)$ of $\mathrm{Y}$ (original spectrum of $\mathrm{Y}$ ).

$$
\begin{aligned}
& \mathrm{X} / \mathrm{X}^{\prime}+\mathrm{Y}^{\prime} \mathrm{X}^{\prime}-\mathrm{X} / \mathrm{X}^{\prime}=\mathrm{Y} / \mathrm{X}^{\prime} \quad \text { and then } \\
& \mathrm{x} \mathrm{X}^{\prime}=\mathrm{Y}
\end{aligned}
$$

The concentration of $\mathrm{X}$ and $\mathrm{Y}$ can be calculated using the regression equations representing the linear relationship between the zero order $\left(D_{0}\right)$ absorbance of each at its $\lambda_{\max }$ versus the corresponding concentrations of $\mathrm{X}$ and $\mathrm{Y}$.

Ratio difference spectrophotometric method (RDSM)

Lotfy et Hagazy ${ }^{23}$ introduced the ratio difference spectrophotometric method (RDSM), in which the amplitude difference between two points on the ratio spectra of a mixture is directly proportional to the concentration of the component of interest; independence of the interfering component is the basic principle of the ratio difference method.

For a mixture of the two drugs $(\mathrm{X})$ and $(\mathrm{Y}), \mathrm{X}$ can be determined by dividing the spectrum of the mixture by a known concentration of $Y$ as a divisor $\left(Y^{\prime}\right)$. The division will give a new curve that represents $(X+Y) / Y^{\prime}=$ $\mathrm{X} / \mathrm{Y}^{\prime}+\mathrm{Y} / \mathrm{Y}^{\prime}=\mathrm{X} / \mathrm{Y}^{\prime}+$ constant.

By selecting two wavelengths $\left(\lambda_{1}\right.$ and $\left.\lambda_{2}\right)$ on the obtained ratio spectrum and subtracting the amplitudes at these two points the constant $\mathrm{Y} / \mathrm{Y}^{\prime}$ will be cancelled along with any other instrumental error or any interference from the sample matrix.

Suppose the amplitudes at the two selected wavelength are P1 and P2 at $\lambda_{1}$ and $\lambda_{2}$, respectively; by subtracting the two amplitudes the interfering substance $Y$ shows no interference; then;

$\mathrm{P} 1-\mathrm{P} 2=\left[\left(\mathrm{X} / \mathrm{Y}^{\prime}\right){ }_{1}+\right.$ constant $]-\left[\left(\mathrm{X} / \mathrm{Y}^{\prime}\right)_{2}+\right.$ constant $]=\left(\mathrm{X} / \mathrm{Y}^{\prime}\right){ }_{1}-\left(\mathrm{X} / \mathrm{Y}^{\prime}\right)_{2}$.

The concentration of $\mathrm{X}$ is calculated by using the regression equation representing the linear relationship between the differences of ratio spectra amplitudes at the two selected wavelengths versus the corresponding concentration of drug (X). Similarly, Y could be determined by the same procedure using a known concentration of $\mathrm{X}$ as a divisor $\mathrm{X}$ '.

Mean centering of ratio spectra method (MCR)

This is a well-established spectrophotometric method in which mixtures and kinetic profiles could be determined ${ }^{23,25}$. In this method the ratio spectra 
are obtained after which the constant is removed by mean centering of the ratio spectra as follow:

For a mixture of the two drugs $(\mathrm{X})$ and $(\mathrm{Y})$, if there is no interaction among the compounds and Beer's law is obeyed for each compound, it can be written:

$$
\mathrm{A}_{\mathrm{m}}=\mathrm{a}_{\mathrm{X}} \mathrm{C}_{\mathrm{X}}+\mathrm{a}_{\mathrm{Y}} \mathrm{C}_{\mathrm{Y}}
$$

Where $\mathrm{A}_{\mathrm{m}}$ is the vector of the absorbance of the mixture, $\mathrm{a}_{\mathrm{X}}$ and $\mathrm{a}_{\mathrm{Y}}$ are the molar absorptivity vectors of $\mathrm{X}$ and $\mathrm{Y}, \mathrm{C}_{\mathrm{X}}$ and $\mathrm{C}_{\mathrm{Y}}$ are the concentrations of $\mathrm{X}$ and $Y$, respectively.

If $\mathrm{A}_{\mathrm{m}}$ is divided by $\alpha_{\mathrm{Y}}$ corresponding to the spectrum of a standard solution of $\mathrm{Y}$ in binary mixture, the first ratio spectrum is obtained as follow:

$$
\mathrm{B}=\mathrm{A}_{\mathrm{m}} / \mathrm{a}_{\mathrm{Y}}=\mathrm{a}_{\mathrm{X}} \mathrm{C}_{\mathrm{X}} / \mathrm{a}_{\mathrm{Y}}+\mathrm{C}_{\mathrm{Y}}
$$
is zero:

If $\mathrm{B}$ is mean centered $(\mathrm{MC})$, since the mean centering of a constant $\left(\mathrm{C}_{\mathrm{Y}}\right)$

$$
\operatorname{MC}(\mathrm{B})=\operatorname{MC}\left(\mathrm{A}_{\mathrm{m}} / \mathrm{a}_{\mathrm{Y}}\right)=\operatorname{MC}\left(\mathrm{a}_{\mathrm{X}} \mathrm{C}_{\mathrm{X}} / \mathrm{a}_{\mathrm{Y}}\right)
$$

As shown there is a linear relation between the amount of MC(B) and the concentration of $(\mathrm{X})$ in the solution without interfering from the other compound (Y). Similarly, (Y) could be determined through dividing $A_{m}$ by $\mathrm{a}_{\mathrm{x}}$ corresponding to the spectrum of a standard solution of $(\mathrm{X})$ and proceed as before.

Isoabsorpative point spectrophotometric method (IsoM)

The isoabsorpative spectrophotometric method ${ }^{26}$ is a well-established method to determine binary mixtures ${ }^{27}$. This method could be used for simultaneous determination of $(\mathrm{X})$ and $(\mathrm{Y})$ in their binary mixtures. At the isoabsorpative point $\left(\lambda_{\text {iso }}\right)$ the mixture of drugs acts as a single component and gives the same absorbance value as pure drug. Thus, by measuring the absorbance value $\left(\mathrm{A}_{\text {iso }}\right)$ at the chosen $\left(\lambda_{\text {iso }}\right)$, the total concentration of both (X) and $(\mathrm{Y})$ in the mixture could be calculated, while the concentration of $(\mathrm{X})$ in the mixture could be calculated without any interference, by applying other spectrophotometric method. Thus the concentration of $(\mathrm{Y})$ could be calculated by subtraction.

$$
\begin{aligned}
& \mathrm{A}_{\text {iso }}=\mathrm{A}_{X+} \mathrm{A}_{Y=} a_{X i s o} C_{X}+a_{Y i s o} C_{Y}=a_{i s o}\left(C_{X}+C_{Y}\right) \quad \text { at } \lambda_{\text {iso }}, \quad \text { where } \\
& a_{X i s o}=a_{Y i s o} \\
& \text { But } \mathrm{A}_{X}=a_{X} C_{X} \\
& \text { Then } C_{Y}=\left(C_{X}+C_{Y}\right)-C_{X}
\end{aligned}
$$

Absorbance ratio method (ARM)

The absorbance ratio method ${ }^{28}$ is based on the linear relationship between the absorbance ratio value of a binary mixture of $(\mathrm{X})$ and $(\mathrm{Y})$ and the relative concentration of such a mixture using the following equations:

$\mathrm{C}_{\mathrm{X}}=\left(\mathrm{Q}_{1}-\mathrm{b}_{1} / \mathrm{a}_{1}\right)\left(\mathrm{A}_{\text {iso }} / \mathrm{a}_{\text {iso }}\right) \times 10^{3}$

$\mathrm{C}_{\mathrm{Y}}=\left(\mathrm{Q}_{2}-\mathrm{b}_{2} / \mathrm{a}_{2}\right)\left(\mathrm{A}_{\text {iso }} / \mathrm{a}_{\text {iso }}\right) \times 10^{3}$

Where $\mathrm{Q}_{1}=\mathrm{A}_{1} / \mathrm{A}_{\text {iso }}$ for $1^{\text {st }}$ component $(\mathrm{x}), \mathrm{Q}_{2}=\mathrm{A}_{2} / \mathrm{A}_{\text {iso }}$ for $2^{\text {nd }}$ component $(\mathrm{y})$.

$\mathrm{C}_{\mathrm{X}}, \mathrm{C}_{\mathrm{Y}}=$ concentrations of CIP and HYD, respectively.

$\mathrm{A}_{\text {iso }}=$ absorbance at isoabsorpative point.

$\mathrm{a}_{\mathrm{iso}}=$ absorptivity at isoabsorpative point $=\mathrm{A}_{\mathrm{iso}} / \mathrm{C}_{\mathrm{X}}+\mathrm{C}_{\mathrm{Y}^{*}}$

$a_{1}=$ slope of regression equation $\left(Q_{1}\right.$ vs. $\left.C_{X} / C_{X}+C_{Y}\right)$.

$\mathrm{a}_{2}=$ slope of regression equation $\left(\mathrm{Q}_{2}\right.$ vs. $\left.\mathrm{C}_{\mathrm{Y}} / \mathrm{C}_{\mathrm{X}}+\mathrm{C}_{\mathrm{Y}}\right)$.

$b_{1}, b_{2}=$ intercept values of these regression equations. and $\lambda_{2}$.

$A_{1}$ and $A_{2}$ denote the absorbances of the mixture solution measured at $\lambda_{1}$

In these formula $\left(10^{3}\right)$ was for the conversion of concentration from $\mathrm{mg} /$ $\mathrm{mL}$ to $\mu \mathrm{g} / \mathrm{mL}$.

\section{EXPERIMENTAL}

\section{Apparatus and software}

Shimadzu - UV 1800 double beam UV-Visible spectrophotometer (Japan) with matched $1 \mathrm{~cm}$ quartz cells at 200-800 nm range was used for all absorbance measurements. Spectra were automatically obtained by Shimadzu UV-Probe 2.32 system software. For the mean centering for ratio spectra method, Matlab ${ }^{\circledR}$ Version 7.9 was used.

\section{Chemicals and reagents}

Pure samples

Ciprofloxacin hydrochloride (CIP) was kindly supplied by Egyptian International Pharmaceutical Industries Co. (EIPICO), Cairo, Egypt, While Hydrocortisone (HYD) was kindly supplied by Sigma Pharmaceutical Industries Limited, Al-Monofeya, Egypt. Their purity was found to be 99.86 \pm 0.85 and $100.52 \pm 0.64$ for CIP and HYD respectively by the official methods 1 , respectively.

Market sample

Ciprocort ${ }^{\circledR}$ ear drops, labeled to contain $10 \mathrm{mg}$ of HYD, 2.3mg of CIP per $1 \mathrm{~mL}$ (Batch number: 1601001), was manufactured by European Egyptian Pharmaceutical Industries (EEPI), Alexandria, Egypt.

Solvents

Spectroscopic analytical grade methanol was supplied from (S.d.finechem limited- Mumbai).

\section{Standard solutions}

Stock solutions

Stock solutions of CIP and HYD were prepared in a solvent mixture of methanol: water $(80: 20 \mathrm{v} / \mathrm{v})$, of concentration $1 \mathrm{mg} / \mathrm{mL}$ and $0.5 \mathrm{mg} / \mathrm{mL}$, respectively.

Working solutions

Working solutions were freshly prepared by dilution from the stock solutions with solvent mixture to get $(20 \mu \mathrm{g} / \mathrm{mL})$ of both drugs.

\section{Procedure}

Spectral characteristics of CIP and HYD

The zero-order absorption spectra ( $D_{0}$ ) of $5 \mu \mathrm{g} / \mathrm{mL}$ CIP and HYD solutions were recorded against solvent mixture as a blank.

Construction of calibration curves

Different aliquots were transferred from the working solutions $(20 \mu \mathrm{g} / \mathrm{mL})$ into a series of $10 \mathrm{~mL}$ volumetric flasks then completed to volume with solvent mixture to form solutions equivalent to $(2-14 \mu \mathrm{g} / \mathrm{mL})$ of CIP and $(1-14 \mu \mathrm{g} / \mathrm{mL})$ of HYD. The spectra of the prepared standard solutions were scanned from 200-400 $\mathrm{nm}$ and stored in the computer.

\section{For EXRSM}

Calibration curves were constructed relating the $\mathrm{D}_{0}$ absorbance at 278.6 $\mathrm{nm}$ and $243 \mathrm{~nm}$ for CIP and HYD respectively, versus the corresponding concentrations and the regression equations were computed.

\section{For RDSM}

The stored spectra of CIP were divided by the spectrum of $5 \mu \mathrm{g} / \mathrm{mL}$ HYD, while HYD spectra were divided by the spectrum of $6 \mu \mathrm{g} / \mathrm{mL}$ CIP. Calibration curves were constructed by plotting the difference between the amplitude ratio difference $\left(\Delta P_{2798-2417}\right)$, and $\left(\Delta P_{2417-2215}\right)$ for the CIP and HYD, respectively, versus the corresponding concentrations and the regression equations were computed.

\section{For MCR}

The ratio spectra obtained from RDSM were exported to Matlab to perform mean centering with respect to wavelength and the mean centered ratio spectra (MC) were obtained for both drugs. Calibration curves were constructed by plotting maximum peak amplitude of MC at $279.8 \mathrm{~nm}$ and $241.7 \mathrm{~nm}$ for CIP and HYD respectively versus the corresponding concentrations and the regression equations were computed.

For IsoM

Calibration curves were constructed by plotting the $\mathrm{D}_{0}$ absorbance at isoabsorpative point $256.2 \mathrm{~nm}\left(\lambda_{\text {iso }}\right)$ for HYD versus the corresponding concentrations and the regression equation was computed.

The second derivative $\mathrm{D}^{2}$ was recorded for the CIP stored spectra $(\Delta \lambda$ $=8$ ) against solvent mixture as a blank. Calibration curve was constructed by plotting peak amplitude of $\mathrm{D}^{2}$ spectra at $256.2 \mathrm{~nm}$ for CIP versus the corresponding concentrations and the regression equation was computed.

\section{For ARM}

Calibration curve was constructed relating the $\mathrm{D}_{0}$ absorbance at $330 \mathrm{~nm}$ for CIP versus the corresponding concentrations and the regression equation was computed.

Application to laboratory prepared mixtures

Aliquots equivalent to $(50.0,20.0,20.0,80.0,40.0,90.0,60.0$ and $20 \mu \mathrm{g})$ of CIP and (50.0, 40.0, 60.0, 40.0, 60.0, 30.0, 40.0 and $100 \mu \mathrm{g})$ of HYD were transferred from their working solutions $(20 \mu \mathrm{g} / \mathrm{mL})$ into a series of $10 \mathrm{~mL}$ measuring flasks, mixed well in the same order and completed to volume with solvent mixture of methanol: water $(80: 20 \mathrm{v} / \mathrm{v})$ to form the mixtures solutions. The spectra of the prepared standard solutions were scanned from $200-400 \mathrm{~nm}$ and stored in the computer.

Application to pharmaceutical preparation

One milliliter was accurately transferred from the pharmaceutical dosage 
form solution to a $100 \mathrm{~mL}$ volumetric flask and diluted to the mark with solvent mixture methanol: water $(80: 20 \mathrm{v} / \mathrm{v})$ to get $23 \mu \mathrm{g} / \mathrm{mL}$ of CIP and $100 \mu \mathrm{g} / \mathrm{mL}$ of HYD; the prepared solution was filtered through $0.45 \mu \mathrm{m}$ Millipore syringe membrane filter. An appropriate dilution was then made with the same solvent to prepare the working solution containing of $2.3 \mu \mathrm{g} / \mathrm{mL}$ CIP and $10 \mu \mathrm{g} / \mathrm{mL}$ HYD. Six replicates for each experiment were done. The concentrations of pure CIP and HYD were calculated from their corresponding regression equations. When carrying out the standard addition technique, different known concentrations of pure standard CIP and HYD were added to the pharmaceutical dosage form before proceeding in the previously mentioned methods.<smiles>O=C(O)c1cn(C2CC2)c2cc(N3CCNCC3)c(F)cc2c1=O</smiles>

(a)<smiles>C[C@]12CCC[C@@]1(C)[C@H]1C=CC3=CC(=O)CC[C@]3(C)[C@H]1C[C@@H]2O</smiles>

(b)
Fig. 1. The chemical structures of (a) Ciprofloxacin hydrochloride and (b) Hydrocortisone.

\section{RESULTS AND DISCUSSION}

The aim of this work was to develop simple, sensitive, selective and precise spectrophotometric methods for simultaneous estimation of CIP and HYD in their pure form and ophthalmic solution. The zero-order absorption spectra $\left(\mathrm{D}_{0}\right)$ of CIP and HYD showed overlapping, which couldn't be resolved by first $\left(D^{1}\right)$ or second $\left(D^{2}\right)$ derivative, Fig. 2. So, different spectral manipulating techniques have been applied including two recently developed methods.
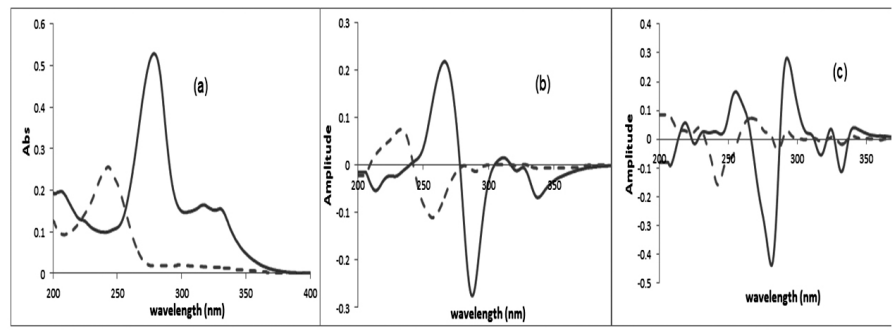

Fig. 2. UV spectra of $5 \mu \mathrm{g} / \mathrm{mL}$ of each CIP ( $\quad$ ) and HYD (- - -), (a) zero order spectra $\mathrm{D}_{0}$, (b) $1^{\text {st }}$ derivative spectra $\mathrm{D}^{1}$, (c) $2^{\text {nd }}$ derivative spectra $\mathrm{D}^{2}$.

\section{EXRSM}

The Extended ratio subtraction method (EXRSM) was used for the determination of the binary mixture of CIP and HYD. In the extended ratio subtraction, the first step is applying the well-established ratio subtraction method (RS) where the mixture's spectrum is divided by using certain concentration of one component as a divisor, where the constant value is calculated along the plateau region which is parallel to the baseline $\geq \pm 2 \mathrm{~nm}$ (corresponding to the maximum peak of the divisor in its zero order), then subtracted from the ratio spectra followed by multiplication by the divisor. In ratio subtraction and extended ratio subtraction method, each component of interest is recovered in its zero order spectra and measured at its $\lambda_{\max }$ to minimize the noise error.

HYD can be determined by dividing the spectrum of the binary mixture by a known concentration of CIP as a divisor $(6 \mu \mathrm{g} / \mathrm{mL}$ of CIP). The constant obtained from the division was measured at the plateau $(330-350 \mathrm{~nm})$. By subtracting this constant value, then multiply the obtained curve after subtraction by the spectrum of $6 \mu \mathrm{g} / \mathrm{mL}$ of CIP (the divisor), therefore we can recover the zero order absorption spectrum HYD present in the mixture, Fig. 3 , and measured it at its $\lambda_{\text {max }}(243 \mathrm{~nm})$.

To determine CIP in the binary mixtures, the obtained $\mathrm{D}$ spectrum of HYD was divided by a known concentration of HYD as a divisor ( $5 \mu \mathrm{g} / \mathrm{mL}$ of HYD) to get the constant value at $(225-255 \mathrm{~nm})$. Then by dividing the spectrum of the binary mixture by the spectrum of $5 \mu \mathrm{g} / \mathrm{mL}$ of HYD (the divisor), the division will give the previously obtained constant. By subtracting this constant, then multiply the obtained curve after subtraction by the spectrum of $5 \mu \mathrm{g} / \mathrm{mL}$ of HYD (the divisor), therefore we can obtain the zero order absorption spectrum CIP present in the mixture, Fig. 4, and measured it at its $\lambda_{\max }(278.6 \mathrm{~nm})$.
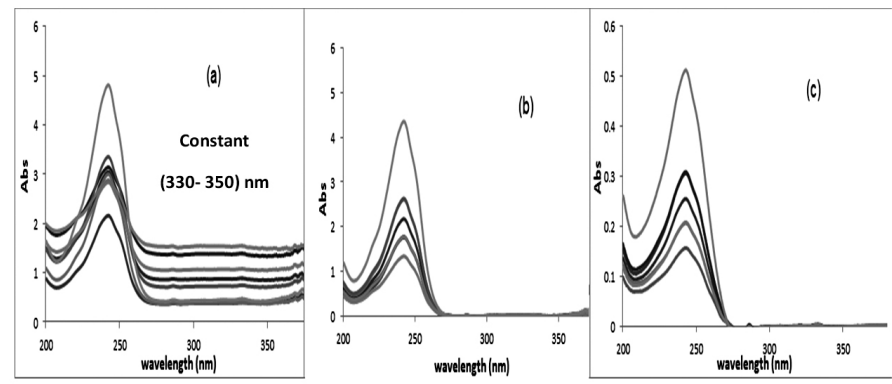

Fig.3. (a) Ratio spectra of laboratory prepared mixtures of CIP and HYD using $6 \mu \mathrm{g} / \mathrm{mL}$ of CIP as a divisor, (b) Ratio spectra after subtraction of the constant, (c) The obtained zero order spectra of HYD in the laboratory prepared mixtures after ratio subtraction.
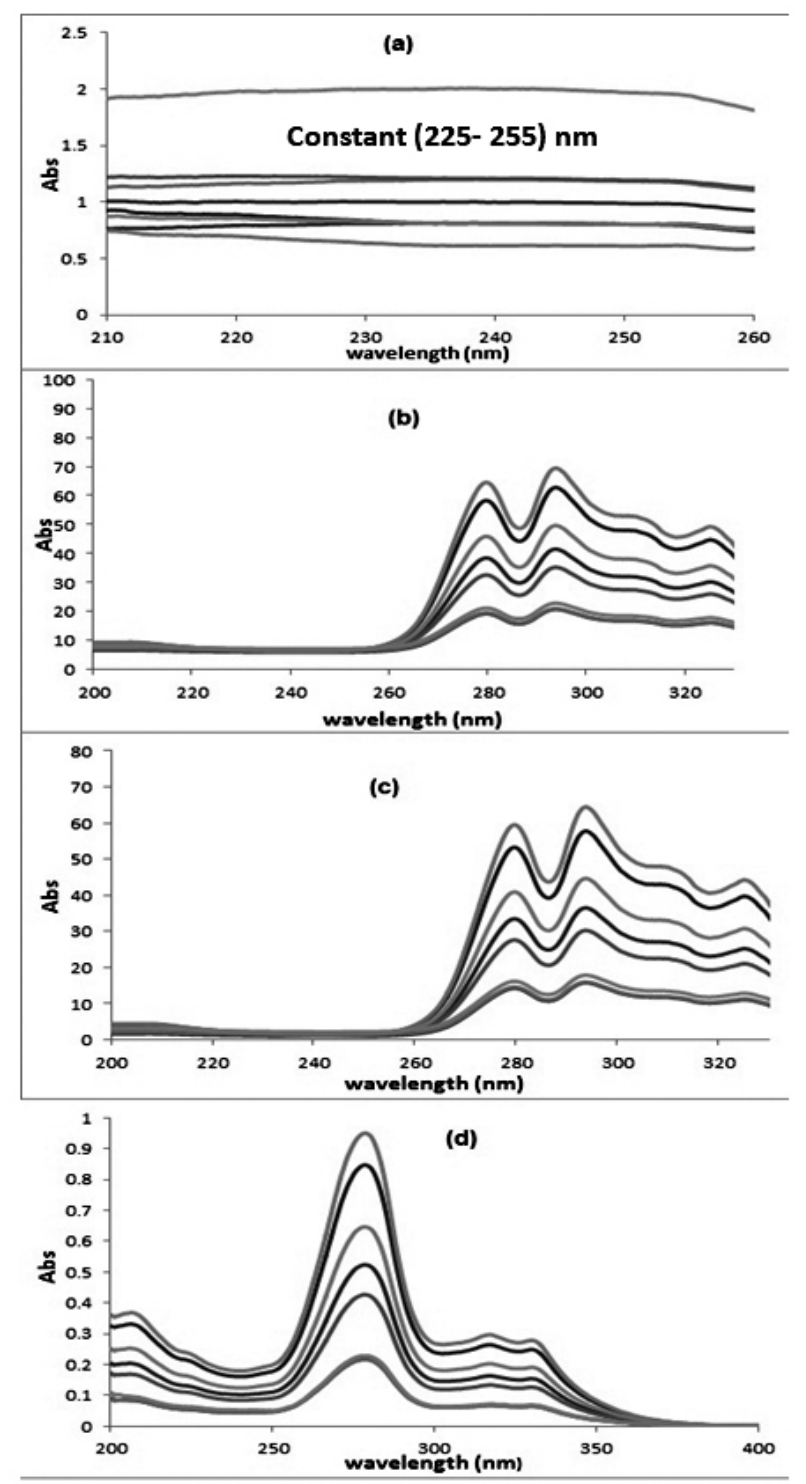

Fig.4. (a) Ratio spectra of obtained spectra of HYD using $5 \mu \mathrm{g} / \mathrm{mL}$ of HYD as a divisor (b) Ratio spectra of laboratory prepared mixtures of CIP and HYD using $5 \mu \mathrm{g} / \mathrm{mL}$ of HYD as a divisor, (c) Ratio spectra after subtraction of the constant, (d) The obtained zero order spectra of CIP in the laboratory prepared mixtures after extended ratio subtraction. 
The concentration of CIP and HYD were calculated using the regression equations representing the linear relationship between the zero order $\left(\mathrm{D}_{0}\right)$ absorbance of each at 278.6 and $243 \mathrm{~nm}$ versus the corresponding concentrations of CIP and HYD, respectively.

Different concentrations of CIP $(3,6$ and $9 \mu \mathrm{g} / \mathrm{mL})$ and of $\operatorname{HYD}(3,5$ and $7 \mu \mathrm{g} / \mathrm{mL}$ ) were tested as a divisor but the concentrations $6 \mu \mathrm{g} / \mathrm{mL}$ of CIP and $5 \mu \mathrm{g} / \mathrm{mL}$ of HYD gave minimum noise, smoother ratio spectra and maximum sensitivity.

\section{RDSM}

The overlapped spectra of the CIP and HYD suggested that ratio difference spectrophotometric method as a suitable method for their simultaneous determination. RDSM depends on measuring the difference between two amplitude values at two wavelengths in one step using the ratio spectra, so eliminates the derivative steps and therefore the signal to noise ratio is enhanced. The linearity of the amplitude values at each of the chosen wavelength against the corresponding concentration should be checked to ensure minimal noise to signal ratio at these wavelengths. By applying the ratio difference method, the difference between the amplitude values is measured by subtraction the two values at two selected wavelength, so the noise will be cancelled.

For the determination of CIP concentration by this method, the only requirement was the contribution of the CIP and HYD at the two selected wavelengths (279.8 and $241.7 \mathrm{~nm}$ ) where the ratio spectrum of the HYD showed the same amplitudes (constant) whereas the CIP showed significant difference in these two amplitude values at these two selected wavelengths with concentration. Similarly, another two wavelengths (241.7 and $221.5 \mathrm{~nm}$ ) were selected for the estimation of the HYD.

The CIP solutions $(2-14 \mu \mathrm{g} / \mathrm{mL})$ spectra were divided by the spectrum of HYD $(5 \mu \mathrm{g} / \mathrm{mL})$ and the HYD solutions $(1-14 \mu \mathrm{g} / \mathrm{mL})$ spectra were divided by the spectrum of CIP $(6 \mu \mathrm{g} / \mathrm{mL})$, Fig. 5. The concentration of CIP was calculated by using the regression equation representing the linear relationship between the differences of these ratio spectra amplitudes at the two selected wavelengths versus the corresponding concentration of drug CIP. Similarly, HYD could be determined in the same manner. The divisors concentrations were selected as in (EXRSM). The selected wavelengths were the best regarding average recovery percent when used for the prediction of CIP and HYD concentrations in bulk powder as well as in laboratory prepared mixtures.
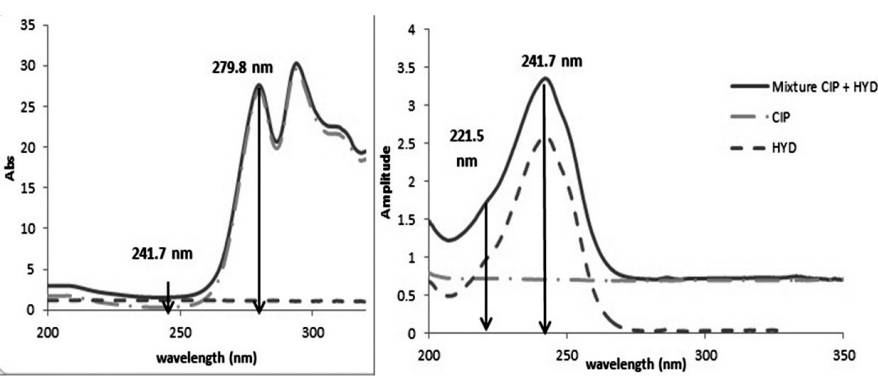

Fig. 5. Ratio spectra of mixture of $5 \mu \mathrm{g} / \mathrm{m}$ of each of CIP and HYD, (a) using $5 \mu \mathrm{g} / \mathrm{mL}$ HYD as a divisor, (b) using $6 \mu \mathrm{g} / \mathrm{mLCIP}$ as a divisor.

\section{MCR}

This method eliminates derivative steps and therefore signal-to-noise ratio is enhanced. The ratio spectra for both drugs obtained from (RDSM) were mean centered in the range (200-330 nm), Fig. 6; the spectra from 330-400 were eliminated as it affected the linearity of the MC curves. The concentration of both drugs was calculated by using the regression equation representing the linear relationship between (MC) at $279.8 \mathrm{~nm}$ and $241.7 \mathrm{~nm}$ for CIP and HYD respectively.

IsoM

The isoabsorpative spectrophotometric method was applied for simultaneous determination of CIP and HYD in their binary mixtures. The total concentration (CIP + HYD) can be measured at the isoabsorpative point $\left(\lambda_{\text {iso }}\right.$ $=256.2 \mathrm{~nm}$ ), Fig. 2 , by using the regression equation representing the linear relationship between $\mathrm{D}_{0}$ absorbance of HYD at $256.2 \mathrm{~nm}$. The concentration of CIP in the mixture could be calculated without any interference, by using the regression equation representing the linear relationship between $\mathrm{D}^{2}$ absorbance of CIP at $256.8 \mathrm{~nm}$. Thus the concentration of HYD was then be calculated by subtraction.

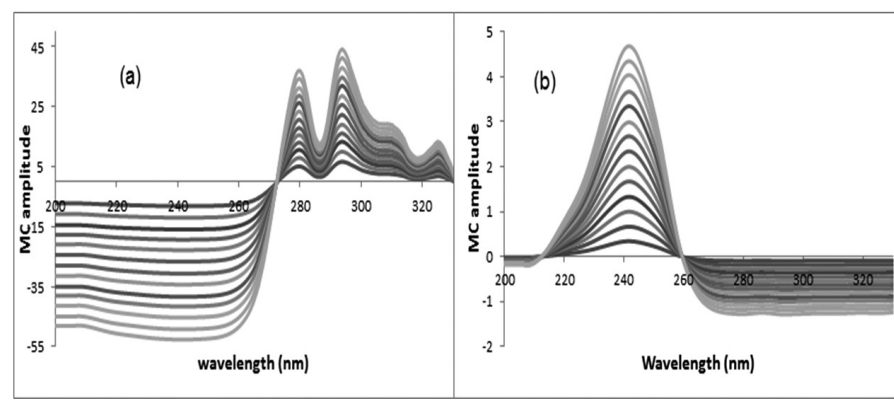

Fig. 6. (a) Mean centered ratio spectra of CIP $(2-14 \mu \mathrm{g} / \mathrm{mL})$, (b) Mean centered ratio spectra of HYD $(1-14 \mu \mathrm{g} / \mathrm{mL})$.

\section{ARM}

The absorbance ratio method was applied to determine the concentration of CIP (Cx) and HYD (Cy) in a binary mixture through the linear relationship between the absorbance ratio value of the binary mixture of $(\mathrm{X})$ and $(\mathrm{Y})$ and the relative concentration in that mixture. The main criteria for the application of the absorbance ratio method are the existence of an isoabsorpative point and selection of optimum wavelengths. For good separation, the method should be applied using the wavelengths $\left(\lambda_{1}, \lambda_{2}, \lambda_{\text {iso }}\right)$ which can fulfill good determination of the components in the binary mixture. The choice of the two wavelengths $(243$ and $330 \mathrm{~nm})$ beside the isoabsorpative point $(256.2 \mathrm{~nm})$ gave the best recovery percentages for determination of laboratory prepared mixtures.

The absorbance of the previous laboratory prepared mixtures at $\lambda$ $(256.2 \mathrm{~nm})$ were plotted against total concentrations of $\left(\mathrm{C}_{\mathrm{X}}\right)$ and $\left(\mathrm{C}_{\mathrm{Y}}\right)$ and the regression equation was computed, to obtain slope of the regression line $\left(\mathrm{a}_{\mathrm{iso}}\right.$ $=0.030$ ).

The absorbance of each solution was measured at $\lambda_{1}(330 \mathrm{~nm}), \lambda_{2}(243 \mathrm{~nm})$ and $\lambda_{\text {iso }}(256.2 \mathrm{~nm})$, the relative absorbance $\left(\mathrm{Q}_{1}=\mathrm{A}_{1} / \mathrm{A}_{\text {iso }}\right)$ were plotted against the relative concentration $\left(\mathrm{C}_{\mathrm{x}} / \mathrm{C}_{\mathrm{X}}+\mathrm{C}_{\mathrm{Y}}\right)$ and the regression equation parameters were computed $\left(b_{1} / a_{1}=0.071\right)$. The relative absorbance $\left(\mathrm{Q}_{2}=\mathrm{A}_{2} / \mathrm{A}_{\text {iso }}\right)$ were plotted against the relative concentration $\left(\mathrm{C}_{\mathrm{Y}} / \mathrm{C}_{\mathrm{X}}+\mathrm{C}_{\mathrm{Y}}\right)$ and the regression equation parameters were computed $\left(\mathrm{b}_{2} / \mathrm{a}_{2}=0.649\right)$.

The corresponding concentration ranges, calibration equations and other statistical parameters for spectrophotometric methods were listed in Table 1.The selectivity of the proposed procedures was assessed by the analysis of laboratory prepared mixtures containing different ratios of the two drugs, where satisfactory results were obtained over the calibration ranges as shown in Table 2 . The proposed procedures were also applied for the determination of CIP and HYD in Ciprocort ${ }^{\circledR}$ ear drops; and were compared to the manufacturer HPLC method ${ }^{29}$, showing no excipients' interference. The validity of the proposed procedures is further assessed by applying the standard addition technique. The results obtained are shown in Table 3 .

Methods validation

Method validation was performed according to ICH guidelines ${ }^{30}$ for the proposed methods as follows:

Range and linearity

The linearity of the proposed methods was evaluated by processing the different calibration curves on three different days. The calibration curves were constructed within concentration ranges that were selected on the basis of the anticipated drugs concentration during the assay of the dosage form. The corresponding concentration ranges, calibration equations and other statistical parameters for both methods were listed in Table 1.

Limits of detection and quantification

The limit of detection (LOD) and limit of quantification (LOQ) were calculated respectively, for both drugs using the proposed methods with a ratio of 3.3and 10 standard deviations of the blank and the slope of the calibration line, Table 1.

Accuracy

To study the accuracy of the proposed methods, procedures under study of linearity, for both drugs using the proposed methods, were repeated three times for the determination of six different concentrations of pure CIP and HYD within the linearity range. The accuracy expressed as percentage recoveries and standard deviation was shown in Table 1. Good accuracy of the developed methods was indicated by the results obtained.

Precision

The intra-day and inter-day precision of the proposed methods were determined by the analysis of three different concentrations of pure CIP and HYD, within the linearity range, by three replicate analyses of three 
pure samples of both drugs on a single day and on three consecutive days, respectively. The results were illustrated in Table 1.

Selectivity

Selectivity was ascertained by analyzing different mixtures containing both drugs in different ratios within the linearity range. Satisfactory results were shown in Table 2 . Good recovery percentages with accepted standard deviations were obtained in all cases which prove the negligible effect of the spectral noise on the constant value using (EXRSM) or (RDSM).

Robustness

The spectral measurements of three concentrations of CIP and HYD (2, $4,6 \mu \mathrm{g} / \mathrm{mL})$ were done using different ratios of methanol in solvent $(75,70$, $65 \%$ ) and analyzed three times using the proposed methods. The methods proved to be robust and the percentage recoveries and standard deviation were calculated, Table 1.

Table 1. Assay parameters and method validation obtained by applying the proposed methods.

\begin{tabular}{|c|c|c|c|c|c|c|c|c|c|}
\hline \multirow[b]{2}{*}{ Parameters } & \multicolumn{2}{|c|}{ EXRSM } & \multicolumn{2}{|c|}{ RDSM } & \multicolumn{2}{|c|}{ MCR } & \multicolumn{2}{|c|}{ IsoM } & \multirow{2}{*}{$\begin{array}{c}\text { ARM } \\
\text { CIP } \\
D_{0}(330 \\
\text { nm) }\end{array}$} \\
\hline & $\begin{array}{c}\text { CIP } \\
D_{0}(278.6 \\
n m)\end{array}$ & $\begin{array}{c}\text { HYD } \\
\mathrm{D}_{0}(243 \\
\mathrm{nm})\end{array}$ & $\begin{array}{c}\text { CIP } \\
P 1-P 2 \\
(279.8- \\
241.7)\end{array}$ & $\begin{array}{c}\text { HYD } \\
P 1-P 2 \\
(241.7- \\
221.5)\end{array}$ & $\begin{array}{c}\text { CIP } \\
\text { MC } \\
(279.8 \\
\text { nm) }\end{array}$ & $\begin{array}{c}\text { HYD } \\
\text { MC } \\
(241.7 \\
\text { nm) }\end{array}$ & $\begin{array}{c}\text { CIP } \\
D^{2}(256.8 \\
\text { nm })\end{array}$ & $\begin{array}{c}\text { HYD } \\
\text { D }_{0}(256.2 \\
n m)\end{array}$ & \\
\hline Calibration range $^{a}$ & $2-14$ & $2-14$ & $2-14$ & $2-14$ & $2-14$ & $1-14$ & $2-14$ & $1-14$ & $2-14$ \\
\hline LOD & 0.136 & 0.084 & 0.185 & 0.122 & 0.131 & 0.054 & 0.192 & 0.163 & 0.130 \\
\hline LOQ & 0.414 & 0.255 & 0.562 & 0.371 & 0.398 & 0.165 & 0.583 & 0.495 & 0.395 \\
\hline Slope & 0.1044 & 0.0512 & 6.3589 & 0.2654 & 3.8564 & 0.3208 & 0.0327 & 0.0301 & 0.0305 \\
\hline Intercept & 0.0042 & -0.0009 & 0.6035 & -0.0041 & 0.2318 & -0.0087 & -0.0039 & 0.0010 & 0.0032 \\
\hline Mean \% & 100.20 & 100.16 & 100.04 & 99.89 & 100.07 & 99.93 & 100.18 & 99.93 & 99.99 \\
\hline RSD & 0.87 & 1.01 & 0.82 & 0.60 & 0.75 & 0.46 & 0.83 & 0.59 & 0.69 \\
\hline $\begin{array}{c}\text { Accuracy } \\
\text { (Recovery \% / RSD) }\end{array}$ & $\begin{array}{l}100.57 \\
/ 0.87\end{array}$ & $\begin{array}{l}99.92 \\
/ 0.47\end{array}$ & $\begin{array}{l}100.22 \\
/ 1.17\end{array}$ & $\begin{array}{l}99.52 \\
/ 0.32\end{array}$ & $\begin{array}{l}100.03 \\
/ 1.13\end{array}$ & $\begin{array}{l}100.16 \\
/ 0.48\end{array}$ & $\begin{array}{l}99.96 \\
/ 1.65\end{array}$ & $\begin{array}{l}99.58 \\
/ 0.58\end{array}$ & $\begin{array}{r}100.21 \\
/ 1.34 \\
\end{array}$ \\
\hline Intra-day precision ${ }^{c}$ & 0.61 & 0.16 & 0.42 & 0.27 & 0.47 & 0.57 & 0.60 & 0.43 & $\begin{array}{c}100.52 \\
/ 0.97\end{array}$ \\
\hline Inter-day precision ${ }^{c}$ & 0.83 & 0.44 & 0.54 & 0.49 & 0.66 & 0.84 & 0.48 & 0.84 & $\begin{array}{l}100.79 \\
/ 1.02\end{array}$ \\
\hline Robustness $^{\mathrm{c}}$ & 0.76 & 0.64 & 0.91 & 0.55 & 0.73 & 0.84 & 0.91 & 1.01 & $\begin{array}{l}99.52 \\
/ 0.93\end{array}$ \\
\hline $\begin{array}{l}\text { Correlation } \\
\text { coefficient (r) }\end{array}$ & 1 & 1 & 0.9999 & 0.9999 & 0.9999 & 1 & 0.9999 & 0.9999 & 0.9999 \\
\hline
\end{tabular}

${ }^{a}$ Eight calibration points $(\mathrm{n}=8)$ in $\mu \mathrm{g} / \mathrm{mL}$.

${ }^{b}$ Average of three experiments.

${ }^{c}$ Relative standard deviations of three samples of CIP and HYD.

$\mathrm{D}_{0}$ : zero order absorbance; P1-P2: difference in amplitude; MC: mean centering amplitude; $\mathrm{D}^{2}$ : second derivative amplitude.

LOD: Limit of detection, LOQ: Limit of quantitation; in $\mu \mathrm{g} / \mathrm{mL}$.

Table 2. Determination of CIP and HYD in laboratory prepared mixtures by applying the proposed methods.

\begin{tabular}{|c|c|c|c|c|c|c|c|c|c|c|}
\hline \multirow{3}{*}{ Ratios } & \multicolumn{2}{|c|}{ EXRSM } & \multicolumn{2}{|c|}{ RDSM } & \multicolumn{2}{|c|}{ MCR } & \multicolumn{2}{|c|}{ IsoM } & \multicolumn{2}{|c|}{ ARM } \\
\hline & CIP & HYD & CIP & HYD & CIP & HYD & CIP & HYD & CIP & HYD \\
\hline & \multicolumn{10}{|c|}{ Recovery \% a } \\
\hline $5: 5$ & 99.65 & 99.96 & 99.01 & 99.56 & 99.00 & 101.40 & 98.40 & 101.60 & 98.65 & 98.88 \\
\hline $2: 4$ & 102.44 & 101.51 & 99.88 & 99.86 & 100.00 & 101.25 & 102.50 & 101.75 & 102.31 & 101.05 \\
\hline $2: 6$ & 101.49 & 99.90 & 99.20 & 101.43 & 99.50 & 101.17 & 101.00 & 102.00 & 99.30 & 98.47 \\
\hline $2: 10$ & 101.49 & 100.37 & 101.41 & 100.72 & 101.50 & 101.19 & 99.00 & 101.70 & 100.35 & 99.64 \\
\hline $8: 4$ & 100.99 & 101.51 & 100.71 & 98.62 & 100.63 & 101.75 & 102.00 & 100.75 & 100.39 & 100.42 \\
\hline $4: 6$ & 101.32 & 100.88 & 100.20 & 99.48 & 100.25 & 102.00 & 101.50 & 99.50 & 100.16 & 99.46 \\
\hline $9: 3$ & 100.75 & 101.50 & 100.60 & 99.59 & 100.56 & 101.67 & 100.89 & 99.33 & 100.19 & 102.18 \\
\hline $6: 4$ & 101.74 & 102.00 & 102.25 & 98.82 & 102.00 & 101.25 & 101.33 & 102.75 & 102.25 & 101.77 \\
\hline $\begin{array}{c}\text { Mean } \\
\pm \mathrm{SD}\end{array}$ & $\begin{array}{l}101.23 \\
\pm 0.82\end{array}$ & $\begin{array}{c}100.95 \pm \\
0.80\end{array}$ & $\begin{array}{l}100.41 \\
\pm 1.09\end{array}$ & $\begin{array}{l}99.76 \\
\pm 0.93\end{array}$ & $\begin{array}{l}100.43 \\
\pm 0.99\end{array}$ & $\begin{array}{l}101.55 \\
\pm 0.32\end{array}$ & $\begin{array}{l}100.83 \\
\pm 1.42\end{array}$ & $\begin{array}{l}101.17 \\
\pm 1.21\end{array}$ & $\begin{array}{l}100.45 \\
\pm 1.28\end{array}$ & $\begin{array}{l}100.23 \\
\pm 1.35\end{array}$ \\
\hline
\end{tabular}

a Average of three experiments. 
Table 3. Application of standard addition technique to the analysis of CIP and HYD in Ciprocort ${ }^{\circledR}$ ear drops (Batch no: 1601001) by applying the proposed methods.

\begin{tabular}{|c|c|c|c|c|}
\hline \multirow[b]{2}{*}{ Methods } & \multicolumn{2}{|c|}{ CIP } & \multicolumn{2}{|c|}{ HYD } \\
\hline & Found $\%{ }^{a} \pm$ S.D & $\begin{array}{c}\text { Pure added } \\
\text { Recovery } \%^{\mathrm{b}} \pm \text { S.D }\end{array}$ & Found $\%^{a} \pm$ S.D & $\begin{array}{c}\text { Pure added } \\
\text { Recovery } \%^{\mathrm{c}} \pm \text { S.D }\end{array}$ \\
\hline EXRSM & $101.28 \pm 0.62$ & $100.43 \pm 0.42$ & $98.35 \pm 0.66$ & $99.87 \pm 0.74$ \\
\hline RDSM & $101.33 \pm 0.94$ & $100.52 \pm 0.19$ & $98.75 \pm 0.73$ & $100.19 \pm 0.27$ \\
\hline MCR & $100.90 \pm 0.93$ & $100.16 \pm 0.23$ & $98.11 \pm 0.78$ & $100.49 \pm 0.36$ \\
\hline IsoM & $101.23 \pm 0.58$ & $100.60 \pm 0.18$ & $98.07 \pm 0.46$ & $100.34 \pm 0.12$ \\
\hline ARM & $101.24 \pm 0.81$ & $100.56 \pm 0.62$ & $98.03 \pm 0.74$ & $100.43 \pm 0.55$ \\
\hline $\begin{array}{c}\text { Manufacturer HPLC } \\
\text { method }^{[29] \mathrm{d}}\end{array}$ & $101.66 \pm 0.81$ & & $98.01 \pm 0.64$ & \\
\hline
\end{tabular}

a Average of six experiments.

${ }^{\mathrm{b}}$ Average of three experiments (CIP added : 2, 4, $6 \mu \mathrm{g}$ ).

${ }^{\mathrm{b}}$ Average of three experiments (HYD added : $1,2,3 \mu \mathrm{g}$ ).

${ }^{\mathrm{d}}$ Manufacturer method is HPLC using RP C18 and mobile phase water: methanol (55:45) pH 2.5 with $\mathrm{o}-\mathrm{H}_{3} \mathrm{PO}_{4}$, flow rate $1.5 \mathrm{ml} / \mathrm{min}$, detection at $240 \mathrm{~nm}$.

Table 4. Statistical comparison of the results obtained by the proposed method and the official methods ${ }^{[1]}$ on Ciprocort ${ }^{\circledR}$ ear drops (Batch no: 1601001).

\begin{tabular}{|c|c|c|c|c|c|c|c|c|c|c|c|}
\hline \multirow[b]{2}{*}{ Items } & \multicolumn{6}{|c|}{ CIP } & \multicolumn{5}{|c|}{ HYD } \\
\hline & EXRSM & RDSM & MCR & IsoM & ARM & $\begin{array}{l}\text { Official } \\
\text { method } \\
\text { (1) }\end{array}$ & EXRSM & RDSM & MCR & IsoM & $\begin{array}{c}\text { Official } \\
\text { method [1] }\end{array}$ \\
\hline Variance & 0.76 & 0.67 & 0.58 & 1.14 & 0.30 & 0.19 & 1.17 & 0.36 & 0.17 & 0.21 & 0.26 \\
\hline SEM & 0.25 & 0.38 & 0.38 & 0.29 & 0.33 & 0.33 & 0.27 & 0.21 & 0.32 & 0.19 & 0.26 \\
\hline$F$ value $(6.094)^{b}$ & 3.909 & 3.497 & 2.943 & 3.583 & 1.566 & & 3.949 & 1.408 & $\begin{array}{c}1.212 \\
(\mathbf{4 . 1 2 0})^{\mathrm{b}}\end{array}$ & $\begin{array}{c}1.331 \\
(\mathbf{4 . 1 2 0})^{\mathrm{b}}\end{array}$ & \\
\hline
\end{tabular}

${ }^{\text {a b }} \mathrm{BP}$ methods for CIP is HPLC method, while for HYD is absorbance method.

${ }^{\mathrm{b}}$ Figures between parentheses represent the corresponding tabulated values of $\mathrm{t}$ and $\mathrm{F}$ at $\mathrm{P}=0.05$.

SEM: Standard error of mean.

Table 5. Results of one way ANOVA for Comparison of the proposed and the manufacturer methods ${ }^{[29]}$ for determination of CIP and HYD.

\begin{tabular}{|c|c|c|c|c|c|}
\hline \multicolumn{2}{|c|}{ Source of variation } & $\begin{array}{c}\text { Degree of } \\
\text { freedom }\end{array}$ & Sum of squares & $\begin{array}{c}\text { Mean } \\
\text { square }\end{array}$ & \multirow{2}{*}{$F$ value a } \\
\hline \multirow{3}{*}{ CIP } & Between columns & 5 & 1.867 & 0.3734 & \multirow{2}{*}{0.5660} \\
\cline { 2 - 5 } & Within columns & 30 & 19.792 & 0.6597 & \\
\cline { 2 - 5 } & Total & 35 & 21.659 & & \multirow{2}{*}{0.2242} \\
\cline { 2 - 5 } HYD & Between columns & 5 & 0.4640 & 0.0928 & \\
\cline { 2 - 5 } & Within columns & 30 & 12.417 & 0.4139 & \\
\cline { 2 - 5 } & Total & 35 & 12.881 & & \\
\hline
\end{tabular}

${ }^{a}$ There was no significance difference between the methods using one-way ANOVA at $\mathrm{p}<0.05$.

Statistical analysis

Table 4 showed statistical comparison of the results obtained by the proposed methods and official methods ${ }^{1}$. The calculated $\mathrm{t}$ and $\mathrm{F}$ values were less than the theoretical ones indicating that there was no significant difference between the proposed and the official methods with respect to accuracy and precision. One-way ANOVA was applied for the purpose of comparison of developed methods; Table 5 shows where no significant difference was observed between the new (EXRSM and RDSM) and the well-established methods.

\section{CONCLUSION}

The main advantage of the new methods (RDSM and EXRSM) over the ratio subtraction method is that the application of the last one requires the extension of one of the two components of the mixture and it is limited to determine the non-extended component only, while (EXRSM) can be applied for the determination of the two components of the mixture (extended and non-extended components) at their $\lambda_{\max }$; and (RDSM) can be applied for the determination of any binary mixture without any limitation or specified requirement except that the two spectra of the proposed drugs 
should be contributed at the chosen wavelengths. Regarding accuracy and reproducibility, the EXRSM showed maximum accuracy and reproducibility over the other applied methods that depend on cancelling the constant such as ratio difference and mean centering since it obtains the original spectra of each component in the binary mixture in its zero order and allow its determination at its $\lambda_{\text {max }}$, but the advantage of RDSM that it doesn't require the presence of an extended component in the mixture as in EXRSM, so it shows a wider range of application. Both new methods proved to be accurate, precise and sensitive as the well-established methods, but they had the advantage of being simpler as they do not require any sophisticated apparatus, as HPLC methods. They eliminate the derivative step, hence enhancing the signal to noise ratio, so they are suitable for computer programs that cannot perform derivative or derivative ratio spectrophotometry. They do not need special program to analyze the data as in case of chemometric and mean centering techniques which require Matlab ${ }^{\circledR}$ program. They do not involve several steps to analyze each drug alone, as in isoabsorpative point method, or other sophisticated calculation, as in absorbance ratio method. As a final conclusion, the proposed methods could be easily applied in quality control laboratories without any preliminary separation step as they showed equal accuracy and precision compared to the manufacturer HPLC method for the simultaneous determination of Ciprofloxacin hydrochloride and Hydrocortisone, in contrast they are of lower cost.

\section{REFERENCES}

1. British Pharmacopoeia, The Stationery Office on behalf of the Medicines and Healthcare products Regulatory Agency MHRA-C Crown Copyright, 2009.

2. S.C. Sweetman (Ed) Martindale: The Complete Drug Reference, Pharmaceutical Press: London, 2005.

3. M. El-Brashy, M. E. Metwally, F. A. El-Sepai, Il farmaco. 59, (2004).

4. G. H. Ragab, A. S. Amin, Spectrochim. Acta. A. 60, (2004).

5. U. lu, S. Tatar, Spectrochim. Acta. A. 72, (2009).

6. E. C. L. Cazedey, D. P. Perez, J. P. Perez, H. R. N.Salgado, Chromatographia. 69, (2009).

7. R. Galarini, L. Fioroni, F. Angelucci, G. R. Tovo, E. Cristofani, J. Chromatogr. A. 1216 (2009).
8. E. F. Elkady, M. A. Mahrouse, Chromatographia. 73, (2011).

9. YL. Feng, C. Dong, J Chromatogr Sci. 42, 9, (2004).

10. F. Faria, M. V.N. de Souza, M. V. de Almeida, M. A.L. de Oliveir, Anal. Chim. Acta. 579, (2006).

11. K.H. Bannefeld, H. Stass, G. Blaschke, J. Chromatogr. B. 692, (1997).

12. J. A. Murillo, A. A. Molina, A. M. de la Peña, I. D. Merás, A. J. Girón, $J$ Fluoresc. 17, (2007).

13. J.L. Beltrán, E. Jiménez-Lozano, D. Barrón, J. Barbosa, Anal. Chim. Acta. 501, (2004).

14. J.M. Lemus Gallego, J. Pérez Arroyo, Anal. Chim. Acta. 460, (2002).

15. E. Grippaa, L. Santinia, G. Castellanob, M.T. Gattoa, M.G. Leonea, L. Sasoa, J. Chromatogr. B. 738, (2000).

16. R. Ha'jkova, P. Solich, J. Dvor`a'k, J. S` ${ }^{\prime}$ 'cha, J. Pharm. Biomed. Anal. 32, 4, (2003).

17. P. Murali, K.Getu, B. Isabel, V.S. Ann, A. Erwin, J. Pharm. Biomed. Anal. 56, 3, (2011).

18. J. L. Gallego, J. P. Arroyo, Chromatographia. 56, 7 (2002).

19. J. M. L. Gallego, J. P. Arroyo, J Liq Chromatogr. R T. 26, 7, (2003).

20. H. Sire'n, T. Seppa"nen-Laakso, M. Ores`ic, J. Chromatogr. B. 871, (2008).

21. L. Li, Zhongguo Yaoshi. 3, (2008).

22. C. Xiulin, Z. Xuan, L. Yuxing, Fujian Meidical Journal. 1, (2002).

23. H. M. Lotfy, M. A. Hagazy, Spectrochim. Acta. A. 96, (2012).

24. M.G.El-Bardicy, H. M. Lotfy, M. A. El-Sayed, M. F. El-Tarras, $J A O A C$ Int. 91, 2, (2008).

25. Afkhami, M. Bahram, Anal. Chim. Acta. 526, (2004).

26. S.V. Erram, H. P. Tipnis, Indian Drugs. 2, 31, (1994).

27. M. R. El-Ghobashy, N. F. Abo-Talib, JAR - Cairo University. 1, (2010).

28. N. Erk, J. Pharm. Biomed. Anal. 27, (2002).

29. European Egyptian Pharmaceutical Industries (EEPI) Quality Control Department, Test Method for Determination of Ciprocort ear drops.

30. International Conference on Harmonization ( $\mathrm{ICH})$, Q2B: Validation of Analytical Procedures: Methodology, 62, US FDA, Federal Register, 1997. 